\title{
Metastatic Undifferentiated Pleomorphic
} Sarcoma

National Cancer Institute

\section{Source}

National Cancer Institute. Metastatic Undifferentiated Pleomorphic Sarcoma. NCI

Thesaurus. Code C4926.

An undifferentiated pleomorphic sarcoma that has spread to other anatomical sites. 